\title{
Long-Range Focal Collateralization of Axons Arising from Corticocortical Cells in Monkey Sensory-Motor Cortex
}

\author{
J. DeFelipe, ${ }^{1}$ M. Conley, ${ }^{2}$ and E. G. Jones \\ Department of Anatomy and Neurobiology, University of California, Irvine, California 92717
}

Small extracellular injections of HRP were placed into a stratum of corticocortical axons situated immediately deep to area $3 b$ of the monkey somatic sensory cortex. This stratum had previously been demonstrated to contain corticocortical fibers linking the cytoarchitectonic fields of the somatic sensory cortex to one another and certain of them to the motor cortex. This method resulted in extremely successful filling of pyramidal cells, thcir axons, collateral axon branches, and terminations in areas $3 b, 1$, and 2 posterior to the injection and in areas $3 a$ and 4 anterior to it.

The major finding was that cells with somata situated in any one of these fields and with principal axons traversing the injection site have long collaterals, primarily in layers III and $V$, which can extend throughout their own cytoarchitectonic field and into one or more other fields. In these fields they give off focused, columnlike concentrations of terminal boutons, which can be separated from one another by $800 \mu \mathrm{m}$ or more. The anterogradely labeled, primary corticocortical fibers, traced forwards into areas 3a and 4 , have virtually identical focal terminations.

These findings indicate that interareal connectivity in the sensory-motor cortex can be effected by the axon branches of single cells rather than by separate groups of cells, and this may form a basis for the convergence of place and modality information on single cells in the sensorimotor cortex, a convergence that is not seen in the thalamic input to this cortex.

Schemes of intrinsic circuitry in the cerebral cortex tend to stress its vertical character. Afferent fibers are held to terminate primarily on cells in middle layers, from which activity is relayed vertically across cortical laminae, conforming to the well-known columnar hypothesis of cortical organization (Lorente de Nó, 1949; Mountcastle, 1957). Vertical, translaminar connectivity of this type has often been regarded as essential for the building up of complexity in receptive field structure of cortical neurons (e.g., Gilbert, 1983), although there is recent evidence that certain aspects of receptive field structure in the cat visual cortex do not depend on interlaminar connections (Malpeli, 1983).

The first somatic sensory cortex (SI) of higher primates is composed of four architectonic areas, areas $3 a, 3 b, 1$, and 2 , each of which to a large extent represents the terminus of a separate channel of afferent information flow from the periphery

Received Mar. 14, 1986; revised June 9, 1986; accepted June 12, 1986

This work was supported by grants NS 10526, NS 21377, and T32 NS 07057 from the National Institutes of Health, United States Public Health Service, and was begun at Washington University, where J. DeFelipe was a Fogarty International Fellow. We thank Bertha McClure, Patricia Callahan, and Kai-Yu Lin for technical help.

Correspondence should be addressed to E. G. Jones at the above address.

1 Present address: Instituto Cajal, Velazquez, 144, Madrid, Spain.

2 Present address: Department of Psychology, Duke University, Durham, NC 27706.

Copyright (c) 1986 Society for Neuroscience $0270-6474 / 86 / 123749-18 \$ 02.00 / 0$
(Jones et al., 1982; Kaas et al., 1979; Phillips et al., 1971; Powell and Mountcastle, 1959; Werner and Whitsel, 1968), because independent sets of thalamic cells provide the subcortical input to each of them (Friedman and Jones, 1981; Jones, 1983; Jones et al., 1982). In anesthetized monkeys the earliest neuronal responses in area $3 \mathrm{a}$ are in response to stimulation of muscle spindle primary afferents, in area $3 \mathrm{~b}$ primarily to slowly adapting cutaneous afferents, in area 1 primarily to rapidly adapting afferents, and in area 2 to afferents from deep tissues. A topographically organized, receptive field map of the contralateral half-body can also be derived or conjectured in each area (Kaas et al., 1979; Nelson et al., 1980).

If the four areas have separate, finely topographically organized inputs and if intracortical information flow is predominately vertical, it becomes difficult to explain why, in unanesthetized monkeys, it is possible to record single units, particularly in areas 1 and 2, with complex receptive fields that imply convergence of place and modality information from the other areas (Gardner and Costanzo, 1980; Hyvärinen and Poranen, 1978; Iwamura et al., 1980, 1983a, b, 1985). In studies based upon anterograde and retrograde axoplasmic transport (Jones and Wise, 1977; Jones et al., 1978), small punctate injections of tracer in any one of the four areas of SI lead to equally small focal patches of terminal and/or cell labeling in anteroposterior alignment in two or more of the other areas, with additional foci often in the area injected (Figs. 1,2). This suggests a complex pattern of corticocortical connections that could form the basis for intracortical modality and place convergence. We now show that comparable, multiple focal patches can be generated by the horizontally disposed intracortical collaterals of single pyramidal cell axons. Preliminary results of this investigation have appeared (Conley and Jones, 1984; DeFelipe et al., 1985).

\section{Materials and Methods}

Two sets of experiments were carried out in cynomolgus (Macaca fascicularis) or pigtailed (Macaca nemestrina) monkeys. In the first set of experiments, small pressure or iontophoretic injections of HRP were made just beneath area $3 b$ of the cerebral cortex in the part of the white matter that autoradiography shows contains a stratum of corticocortical axons linking the fields of the first somatic sensory area to one another and to area 4 of the motor cortex. Those passing to subcortical structures tend to diverge and to become more deeply situated (Figs. 1, 2; see also Fig. 37 in Jones et al., 1978). Under Nembutal anesthesia, micropipettes with tip diameters of $20-50 \mu \mathrm{m}$ and containing 5-20\% HRP (Sigma, type VI) in normal saline were introduced at an angle through the preor postcentral gyrus in 8 cynomolgus monkeys and 2 pigtailed monkeys. Spontaneous neuronal activity and activity elicited by natural peripheral stimulation, usually of the hand, was recorded as the micropipette traversed the cortex and was used to define the part of the body represented in the region traversed and the point of entry into the white matter. Typically, $0.06 \mu 1$ of HRP was ejected via an oil-filled hydraulic system connected to the pipette, or $1-5 \mu \mathrm{A}$ anodal current was applied intermittently over a period of $15-30 \mathrm{~min}$ using a $50-60 \%$ duty cycle. Survival times were $24-48 \mathrm{hr}$, after which animals were perfused with $2.5 \%$ glutaraldehyde and $1 \%$ paraformaldehyde in $0.1 \mathrm{~m}$ phosphate buffer. 


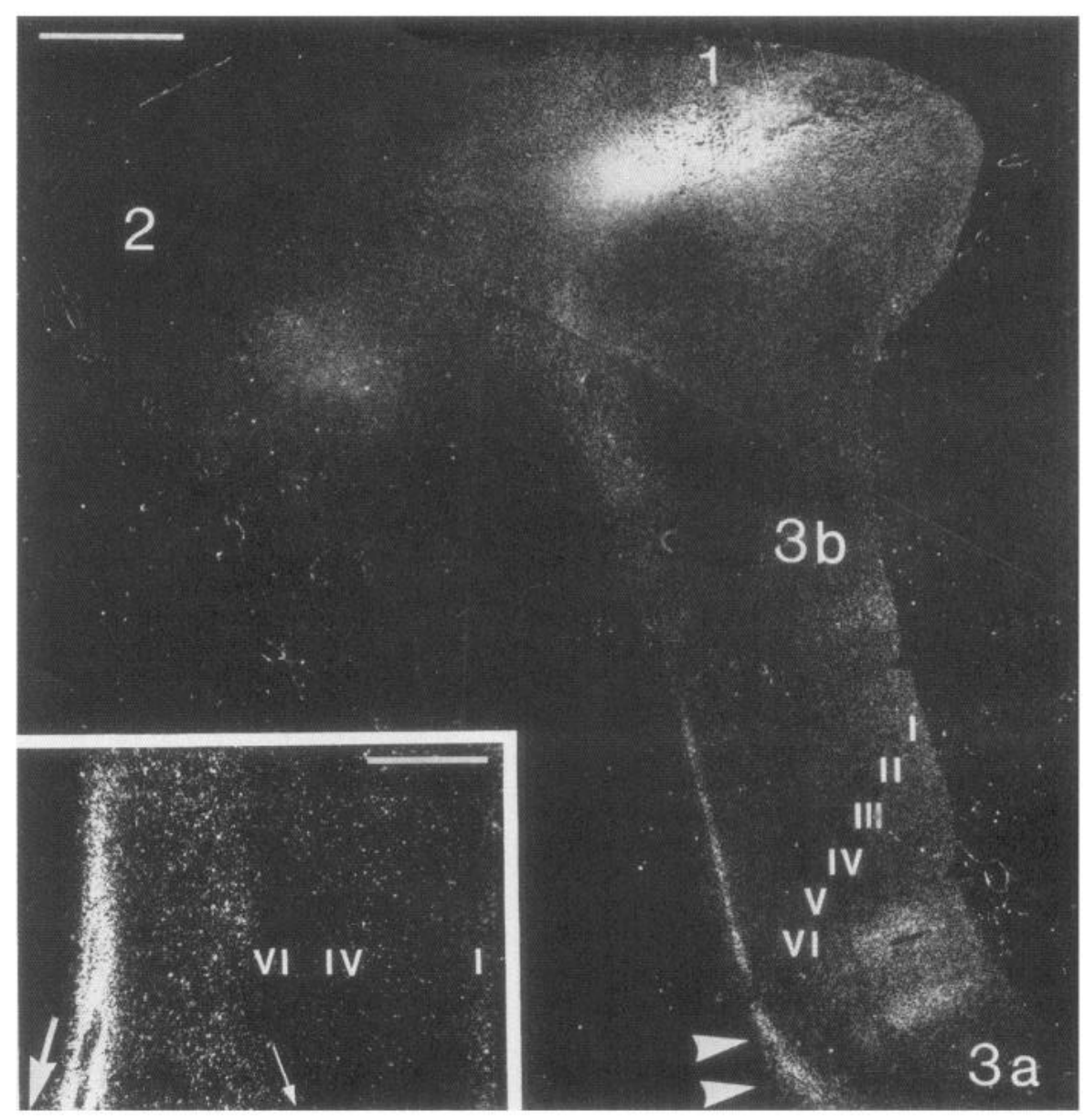

Figure 1. Autoradiograph showing focal patches of corticocortical labeling in areas $3 \mathrm{a}$ and 2 following an injection of tritiated amino acids in area 1. This and all subsequent figures are sagittal sections through the central sulcus with anterior to the right. Arrowheads indicate the compacted bundle of labeled, subcortically projecting fibers. Inset, An adjacent section shows the subcortical fibers (large arrow) diverging from the stratum of corticocortical fibers (small arrow) beneath area $3 \mathrm{~b}$ into which the injections of HRP were made. Bars, 500 $\mu \mathrm{m}$ main figure; $100 \mu \mathrm{m}$ inset.

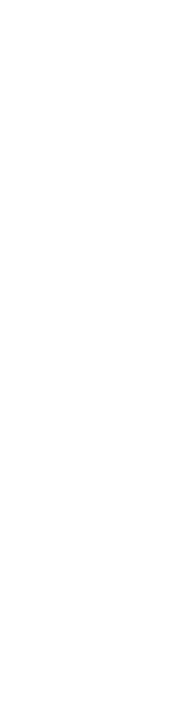

After infiltration with sucrose, the brains were frozen and cut serially at $60 \mu \mathrm{m}$. Sections were reacted for HRP using the cobalt-enhanced diaminobenzidine method (Adams, 1977). Selected slides (usually every fifth) were counterstained with thionin to identify architectonic borders and cortical layers. After injections confined to the stratum of corticocortical axons linking the pre- and postcentral gyri, retrograde labeling of pyramidal cells and their axons occurred in one or more areas of SI and often in area 4 . We chose 35 pyramidal cells in which axons could be traced from labeled somata for $6 \mathrm{~mm}$ or more and in camera lucida drawings reconstructed the stained axon and its collateral branches.

In the second set of experiments, in 2 additional cynomolgus monkeys, an HRP pipette was introduced under physiological control into the hand representation of area 1 and iontophoretic current was applied, as above, to give an injection confined to the gray matter. After a survival period of $36 \mathrm{hr}$ the brains were prepared as above and selected anterogradely labeled axons leaving the injection site were drawn with the camera lucida.

The brains of 31 further cynomolgus and rhesus monkeys from a previous series of experiments (Jones et al., 1978) were examined. These had received small injections of mixed ${ }^{3} \mathrm{H}$-leucine and proline in area $3 a, 3 b, 1,2$, or 4 (Figs. 1, 2A). Between 0.06 and $0.25 \mu 1$ of an equal parts mixture of ${ }^{3} \mathrm{H}$-L-proline and ${ }^{3} \mathrm{H}-\mathrm{L}$-leucine, reconstituted in normal saline to give a final activity of 20 or $50 \mu \mathrm{Ci} / \mu \mathrm{l}$, was injected through micropipettes into defined parts of each area. After a survival of $6 \mathrm{~d}$ the brains were embedded in paraffin, sectioned, and prepared for autoradiography.

\section{Results}

The object of the main series of experiments was to label retrogradely neurons whose axons interconnected the fields of SI and/or whose axons joined certain of the fields of SI to area 4 and vice versa. The patterns of overall connectivity have already been defined (Jones et al., 1978); the connecting axons run in the stratum of corticocortical fibers previously demonstrated and shown in Figures 1 and 2.

The smallest injections of HRP made at the gray-white matter border beneath area $3 \mathrm{~b}$ are approximately $1 \mathrm{~mm}^{3}$ or less in volume, as judged by the extent of extracellular reaction product (Fig. 2B). They are confined to the stratum of corticocortical axons, judged by a comparison with the position of these axons, as labeled in autoradiographs (Fig. $2 A$ ), and by the fact that the vast majority of neurons labeled in the SI and area 4 cortex in these experiments have their somata situated in layer III. Any labeled, subcortically projecting cells would have somata only in layers V and VI (Jones and Wise, 1977). A few putative thalamocortical axons, identified by their similarity to those reported previously (Jones, 1975b) and by their dense terminations in layer IV, were labeled in area $3 \mathrm{~b}$ near the injection site but not in other areas.

The larger injections commonly spread into layer VI of the gray matter of the overlying area $3 \mathrm{~b}$. Such injections usually labeled more afferent axons entering area $3 \mathrm{~b}$ and some in other areas. A certain number of neurons with somata in layers $\mathrm{V}$ and VI were also labeled, in addition to those in layer III. These deep neurons, however, were mainly confined to area $3 \mathrm{~b}$ near the injection site.

The cell bodies of the HRP-labeled cells selected for reconstruction were all in layers IIIA and IIIB of area 4, 3a, 3b, 1, or 2 (Figs. 3, 4, 6-10) and measured $20-25 \mu \mathrm{m}$ in diameter. Their laminar position indicates that none have subcortically projecting axons (Jones and Wise, 1977). The axon, from its origin, descended vertically toward the white matter in most cases. The initial segment measured $1.0-1.5 \mu \mathrm{m}$ until it became myelinated when it reached $2.0-5.0 \mu \mathrm{m}$. The presence of a my- 


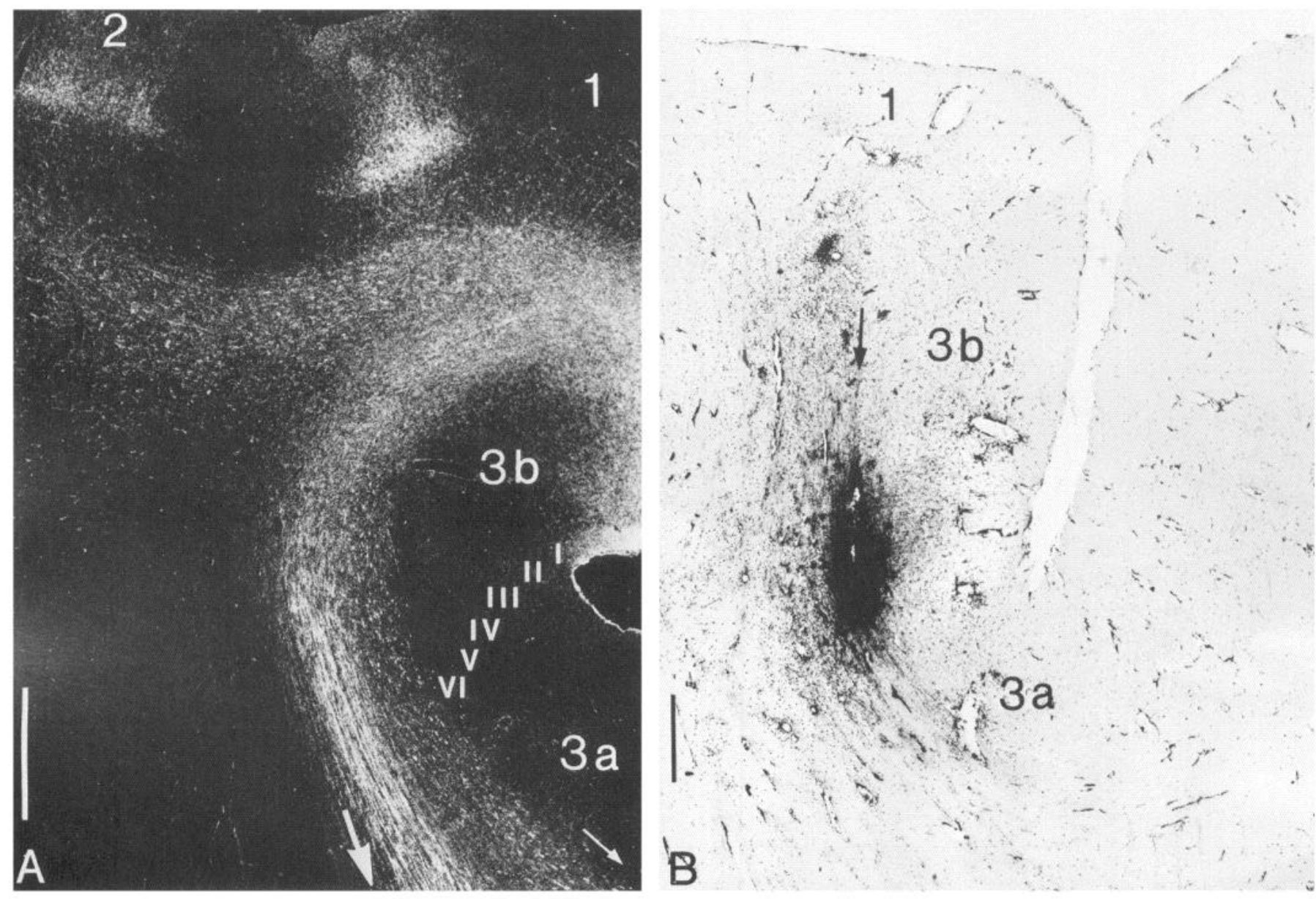

Figure 2. A, Autoradiograph from another animal and at a level medial to Figure 1 showing focal patches of corticocortical labeling in areas 1 and 2 following an injection mainly in area $3 \mathrm{~b}$. The diverging subcortical and anteriorly directed corticocortical fibers are seen at lower right and the posteriorly directed corticocortical fibers at upper left. Bar, $500 \mu \mathrm{m}$. B, Uncounterstained section showing the maximal extent of an HRP injection aimed at the stratum of corticocortical fibers beneath area $3 \mathrm{~b}$. The micropipette track is just visible beneath the arrow. This injection site and extent are typical of all those used for labeling cells in this study. Bar, $1 \mathrm{~mm}$.

elin sheath could usually be detected by regular constrictions of the axon at the nodes of Ranvier and often by faint HRP staining, as though reaction product had spread to the sheath. One to five collaterals arose from the main axon. These could be divided into minor and major collaterals. Minor collaterals were thin, had no obvious myelin sheath, and devolved within a few microns into terminal branches with boutons terminaux, forming a terminal plexus near the cell body, usually just below or to one side of it; major collaterals were myelinated (as judged by the presence of regular constrictions indicative of the nodes of Ranvier), with a diameter of $1.0-3.0 \mu \mathrm{m}$ and lengths of 6 mm or more. Most cells had 1-3 major collaterals with long horizontal or oblique trajectories in layers III or IV and in layers $\mathrm{V}$ or VI; these could run through 2 or more cytoarchitectonic areas of the sensory-motor regions anteriorly, posteriorly, or in both directions. Collaterals initially located in layers III or IV usually gradually ascended towards layer II, while those in deeper layers gradually descended towards layer VI, and 1 or 2 could enter the white matter several hundred microns from the cell body (Figs. 6, 8) or all could continue to their destinations without entering the white matter (Figs. 9, 10) or after only briefly entering it (Fig. 4). In the white matter those running anteriorly ran in the stratum of corticocortical fibers, like the main axons. The main axons and any collaterals in the stratum could usually be traced into the injection site. Those running posteriorly passed in a similar stratum beneath the postcentral sulcus.

Apart from their length, there were 3 distinctive characteristics of the major collaterals: first, the long trajectory (sometimes over $800 \mu \mathrm{m}$ ) over which they gave off no branches (Figs. 4-10); second, the focal nature of the terminal ramifications and of the boutons terminaux to which they gave rise (Figs. 5-10); third, terminal branches arising from widely separated parts of a parent collateral and even from different major collaterals of the same cell in different layers could converge on the same focus of terminations (Figs. 6-10). When only the terminal boutons of these cells are plotted, it becomes evident that the focal patches of terminal boutons are mainly in layers II-IV, which is appropriate for corticocortical cells in these areas (Jones et al., 1978), and are separated by large cortical regions with far fewer or no boutons (Figs. 6-10). The patchy nature of these terminations of single cells is strongly reminiscent of the pattern of anterograde autoradiographic labeling seen after the focal injections of a tracer in one area of SI (Figs. 1, 2A; see also Jones et al., 1978). Patches of transported autoradiographic label are usually columnar or striplike in form, mainly in layers II-IV. Labeled axons entering the patches can reach them by traversing white matter or by running directly through the cortex, exactly like the HRP-labeled collaterals. Moreover, multiple autoradiographically labeled fibers converge on the same patch. 

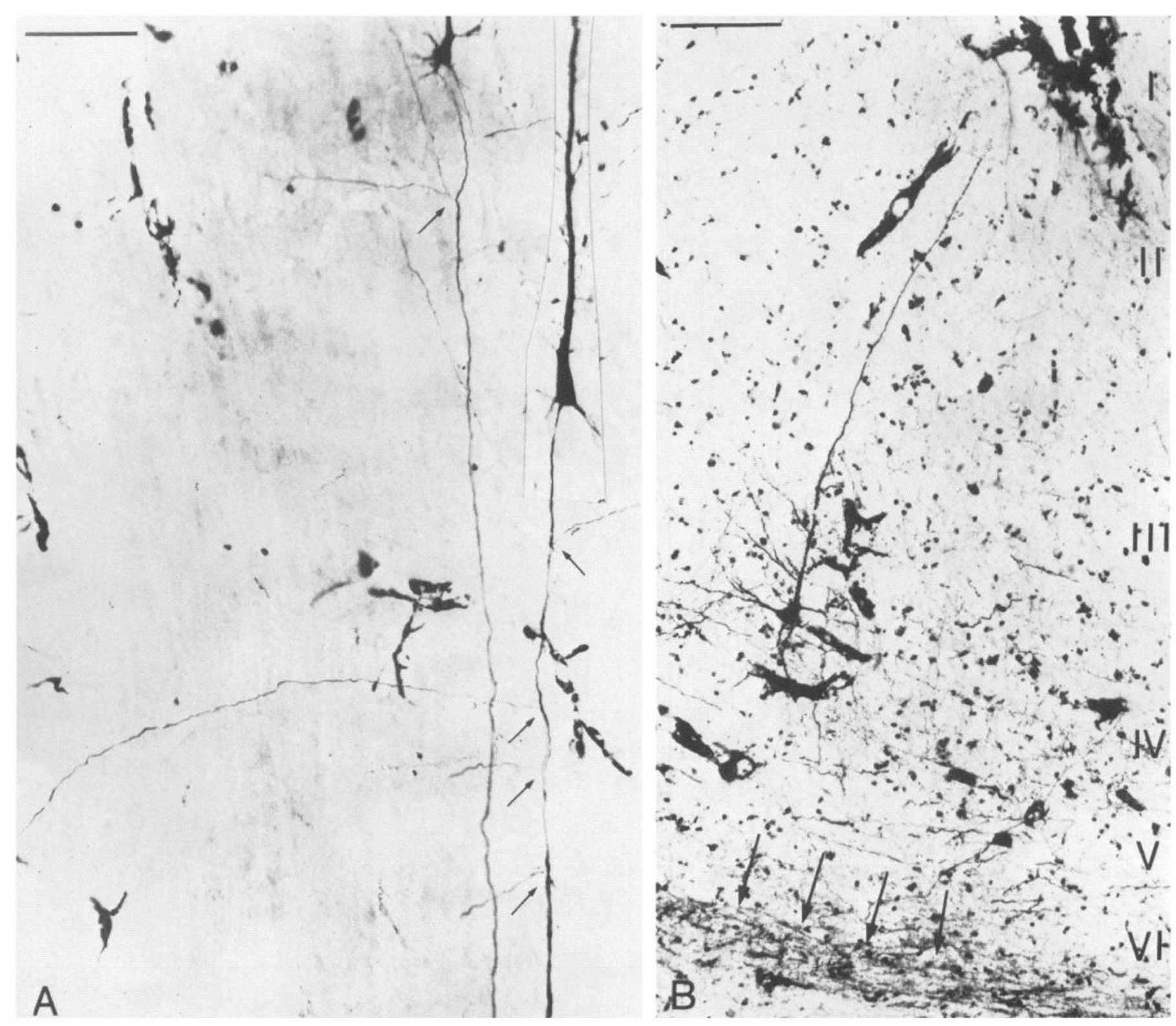

Figure 3. A, Photomicrograph of 2 retrogradely labeled cells in area 2, showing the staining of isolated cells and the origins of several axon collaterals (arrows). Complete reconstructions of these cells are shown in Figure 10. Bar, $100 \mu \mathrm{m}$. B. Photomicrograph showing a retrogradely labeled cell in area $3 \mathrm{a}$ and the anterogradely labeled stratum of corticocortical fibers passing forward to area 4 . Cortical layers were placed by reference to an adjacent counterstained section. Bar, $500 \mu \mathrm{m}$.

The focal, columnlike terminations of HRP-labeled collaterals are dense, primarily on account of the rather large number of terminal branches contributing to them. None of the individual terminal branches gives rise to a dense cluster of boutons terminaux. Instead, each terminal branch presents a relatively sparse linear array of small boutons de passage (Figs. 4, 5). Few or no boutons appear on the ends of short side branches or as clublike appendages. The terminal axons of corticocortical cells are, thus, quite unlike those of thalamocortical axons in this and other areas of the primate cortex (Blasdel and Lund, 1983; Jones, 1975b). The parent collateral and its preterminal branches can adopt virtually any orientation as they approach a terminal focus and are commonly horizontal (Figs. 6-10). The majority of the terminal branches, however, are eventually drawn into a vertical orientation, so that the greater part of a terminal focus is composed of more or less parallel rows of terminal branches and vertical rows of boutons, but boutonal density can vary greatly in foci engendered by the same collateral. There appears to be no obvious distinction between terminal branches innervating layer IV and those innervating the supragranular layers. Most have boutons in both, though some short and descending branches are inevitably restricted to layer IV.

Virtually all labeled cells, irrespective of the cytoarchitectonic field in which their somata lay, had horizontally running major collaterals in both layers III and V (Fig. 11). Terminal ramifications arising from major collaterals in both layers, however, commonly converged on the same focal or columnar terminal domain, and the majority of the terminal boutons in such a domain appeared to be distributed to layers I-IV, and particularly to layers III and IV (to layer III in area 4) (Figs. 4, 5).

Cells with several different patterns of collateral ramification could be identified. To some extent, the different patterns of 


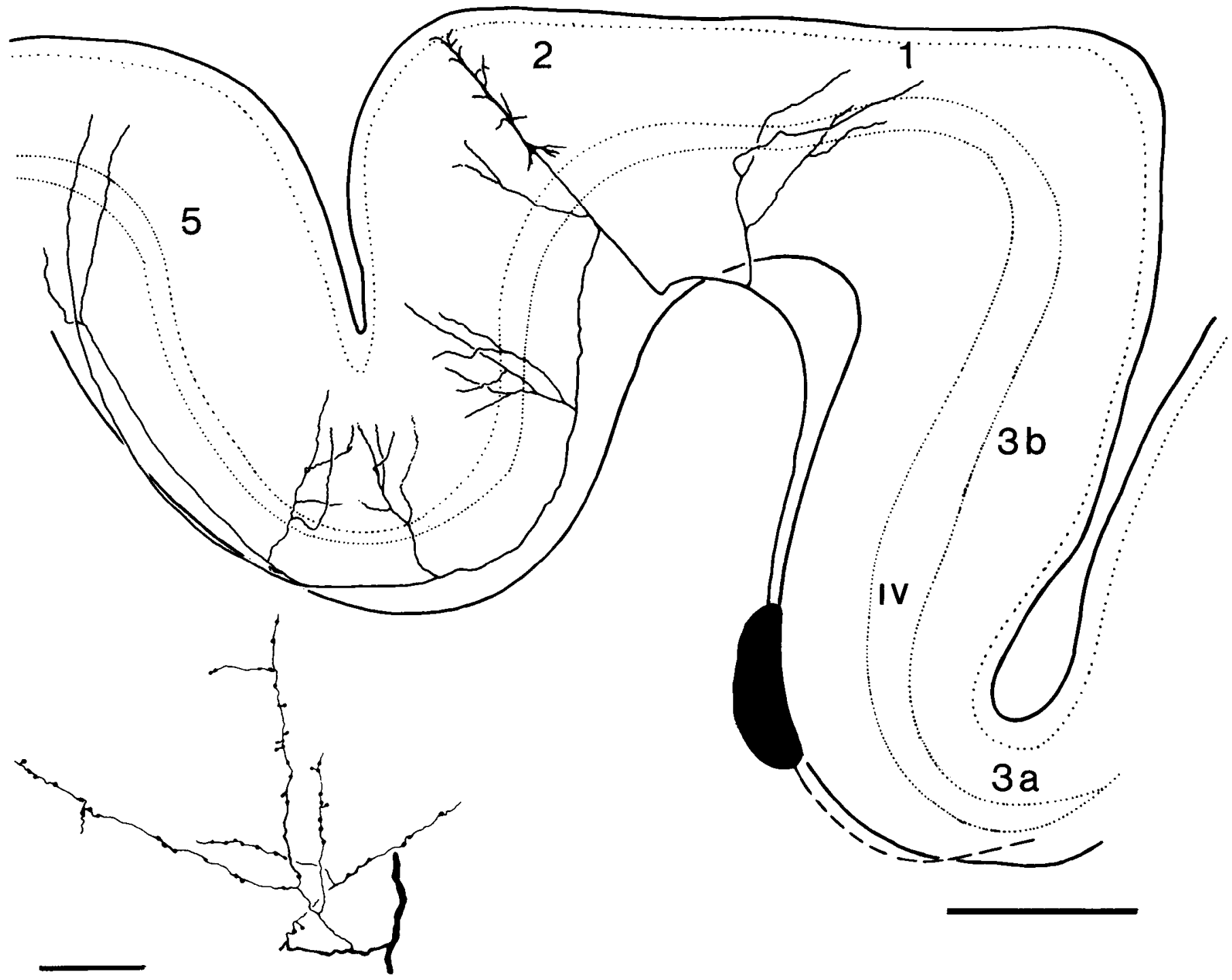

Figure 4. Camera lucida reconstruction made at low magnification, showing typical, retrogradely labeled corticocortical cell in area 2. The injection is indicated in black. Columnlike collateral ramifications are identifiable in areas 1, 2 (3 foci), and 5, and a minor collateral ends in the vicinity of the cell. A photomicrograph of part of the collateral focus in area 1 is shown in Figure $5 B$, and a portion is drawn at high magnification in the inset. Dotted lines indicate layers I and IV, and the broken line indicates the course of anterogradely labeled fibers passing anteriorly from the injection site to areas $3 \mathrm{a}$ and 4 . The axons are artificially thickened in the main figure. Bar, $500 \mu \mathrm{m}$ (main figure); $50 \mu \mathrm{m}$ (inset).

collaterals could be correlated with the architectonic field in which the parent cells' somata lay. Again, only cells whose labeled somata were situated in layer IIIB were considered.

Labeled cells whose somata were situated in area $3 b$ were found to have multiple terminal foci on their collaterals in area $3 \mathrm{~b}$ itself (Fig. 6) and a principal axon projecting forward, presumably to area $3 a$, since area $3 b$ does not project further forward to area 4 (Jones et al., 1978). None of the labeled area $3 \mathrm{~b}$ cells that were recovered, however, was found to send a major collateral backward towards areas 1,2 , or 5 , although it is known that area $3 \mathrm{~b}$ projects to area 1 and possibly to area 2 (Jones et al., 1978). Minor collaterals of labeled cells situated near the area $3 \mathrm{~b}$-area 1 border commonly intruded on area 1 .

Labeled cells whose somata were situated in area $3 \mathrm{a}$ usually gave rise to 1 or 2 collateral terminal foci in area $3 a$ itself and a principal axon projecting backward in the white matter (Fig. 6), presumably to other areas of SI. Occasionally, a collateral branch could be traced anteriorly to close to the area $3 a-4$ border, but no collaterals or principal axons could be traced into area 4 . Area 3a had previously been shown not to project to area 4.

All the labeled cells in area 4 were in the anterior bank of the central sulcus rather than in the more anterior, exposed parts of area 4 (Figs. 7, 8). Most of the cells had collateral branches passing both anteriorly and posteriorly and giving rise to terminal foci in area 4 in both directions. One cell had a collateral that could be traced to a terminal focus in area $3 \mathrm{a}$ as well. All had principal axons that entered the white matter and could be traced posteriorly toward the injection site beneath area $3 \mathrm{~b}$. Most had 1 or 2 collaterals that also entered the white matter. If more than 1 collateral was present, 1 of these commonly passed anteriorly and the other posteriorly, but none could be traced to its destination (Figs. 7, 8).

Labeled cells with somata situated in area 1 (Fig. 9) invariably had 2 or more collaterals directed posteriorly into area 2 in which they gave rise to 2 or more dense focal terminations. One 


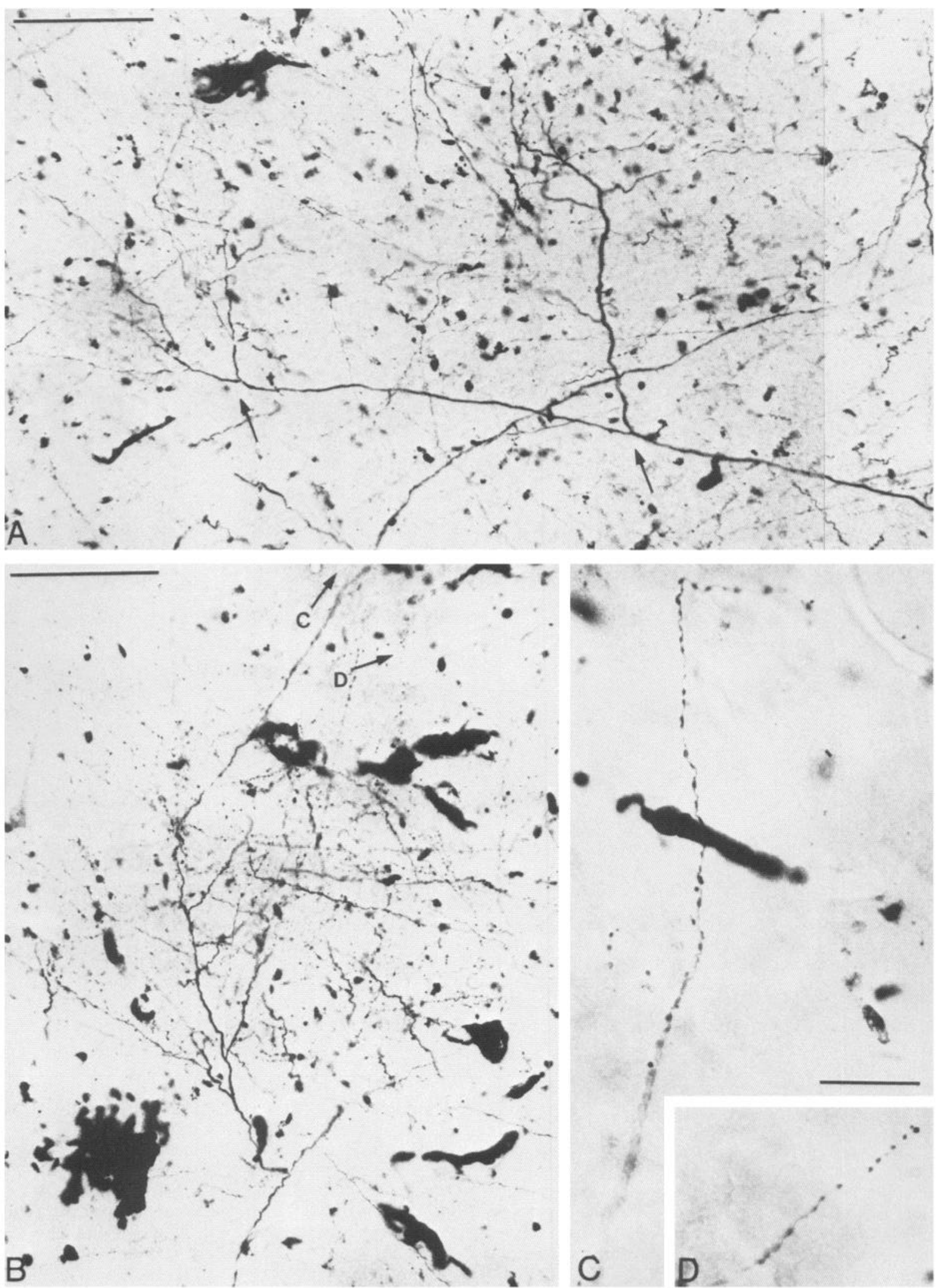

Figure 5. A, Part of a major collateral passing posteriorly from a labeled cell in area 2 and the beginnings (arrows) of 2 focal concentrations of terminal branches to which it gave rise in area 2 . Bar, $100 \mu \mathrm{m}$. B, Major part of the focused zone of collateral terminals generated in area 1 by the cell drawn in Figure 4. Bar, $100 \mu \mathrm{m}$. $C, D$, Higher magnifications of the terminal branches indicated by arrows in $B$, showing their linear rows of boutons terminaux. The branch in $C$ ascended to layer I. Bar, $25 \mu \mathrm{m}$. 


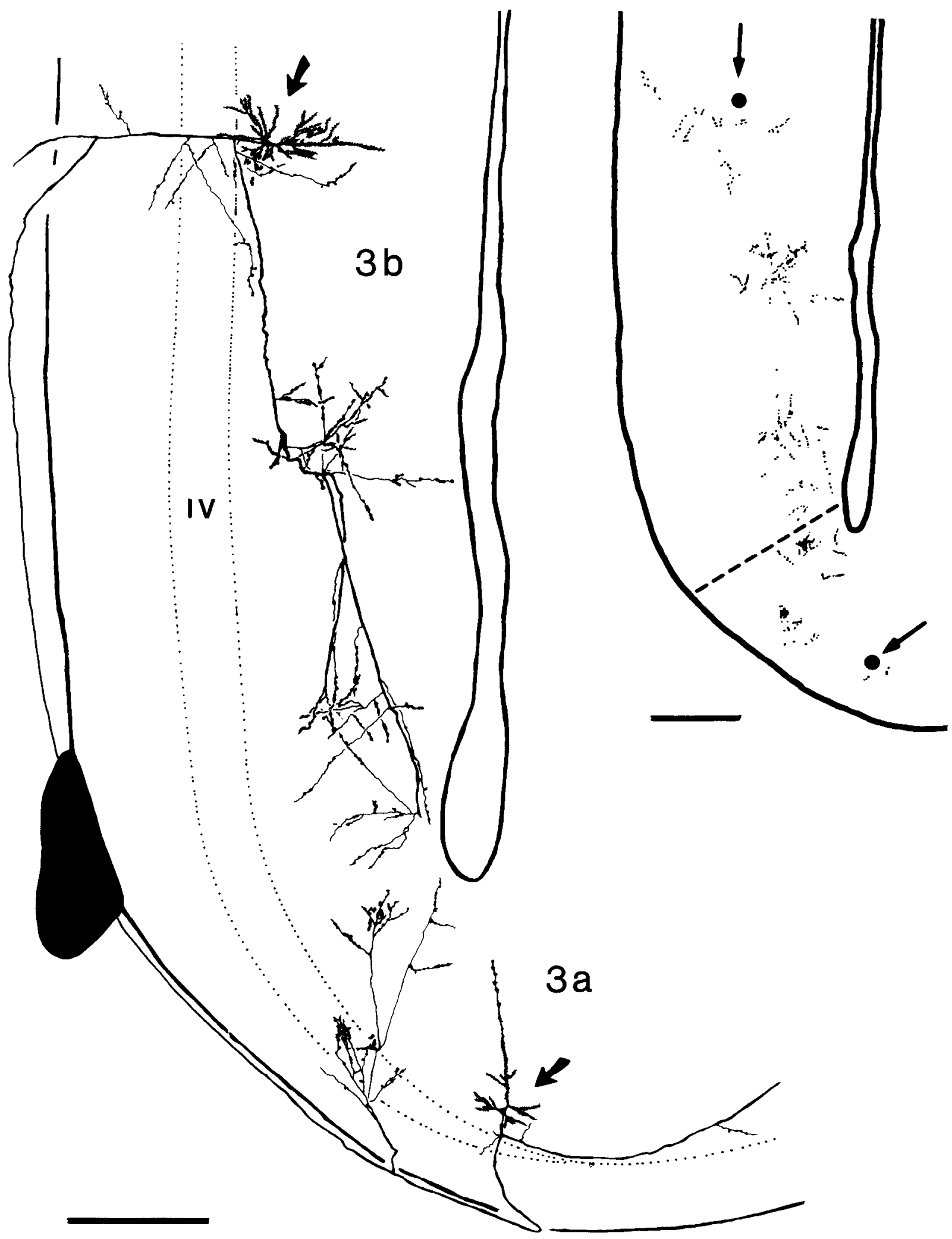

Figure 6. Retrogradely labeled corticocortical cells with somata (arrows) in areas $3 \mathrm{~b}$ and $3 \mathrm{a}$ and focused concentrations of boutons in each area. The boutonal plots were produced from high-magnification drawings of the full collateral ramifications. Each dot indicates one bouton. Bar, $500 \mu \mathrm{m}$.

or more such collaterals could usually be traced without diminution in diameter further posteriorly towards area 5 , but in all cases the labeling ended before obvious terminal ramifications were found. All labeled area 1 cells had a principal axon that could be traced to the injection site and, often but not invariably, a short minor collateral with a limited terminal ramification in the neighboring part of area $3 \mathrm{~b}$.

Labeled cells with somata in area 2 (Figs. 4, 10) invariably 


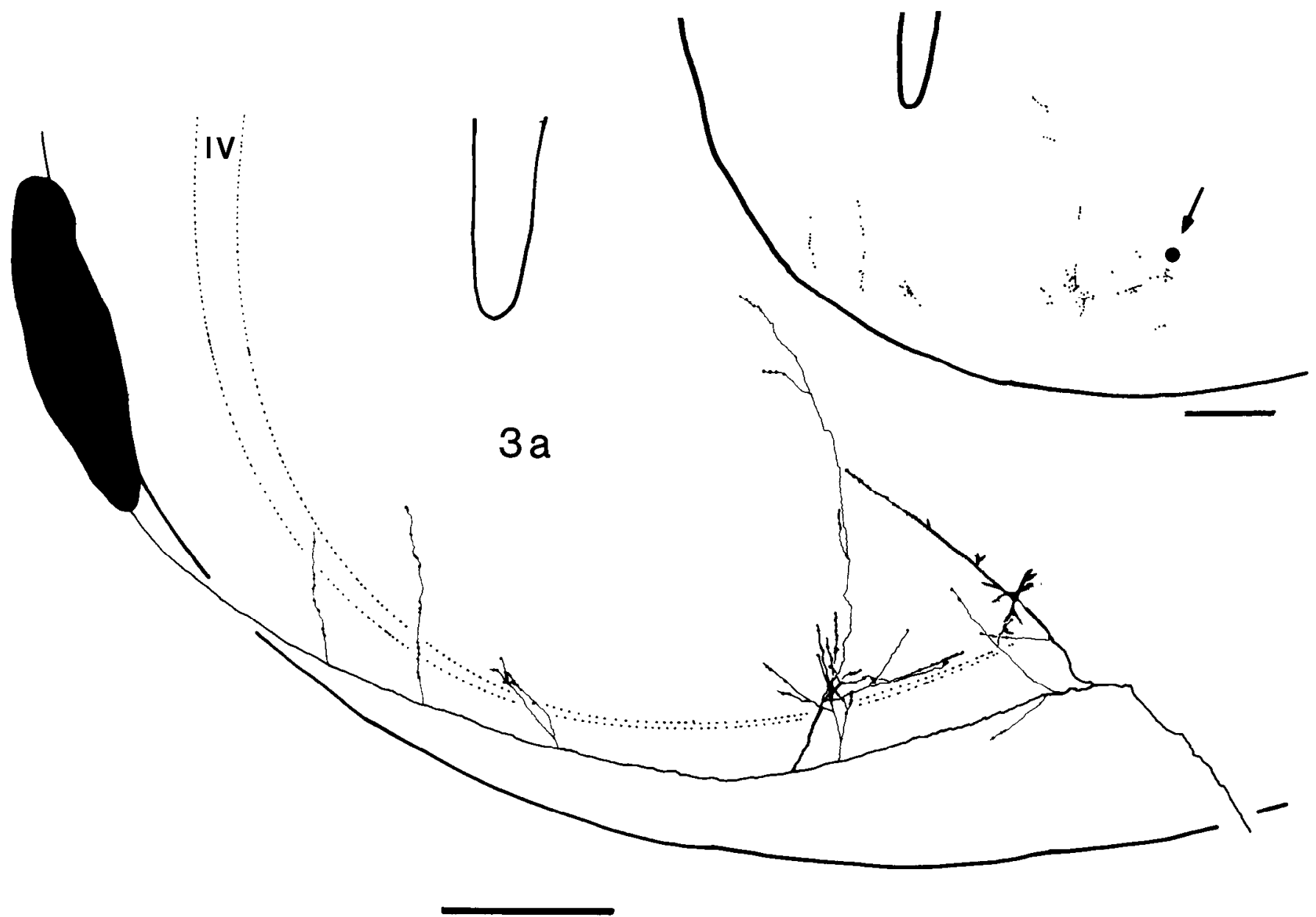

Figure 7. Ketrogradely labeled corticocortical cell with soma at the area $3 a-4$ border and collateral foci in area 3a. A main collateral branch seems to have been injected. Bar, $500 \mu \mathrm{m}$.

had 1,2 , or 3 thick major collaterals passing posteriorly into area 5. All gave rise to multiple terminal foci in posterior parts of area 2. Terminal ramifications could be identified in area 5 as well, in several cases, but labeling of the collaterals often ended before these could be resolved. The majority of labeled area 2 cells also had 1 or 2 major or minor collaterals of variable thickness that passed forward into area 1 . Some ended in dense focal terminations, but on others the terminal boutons were frequently few and sparsely distributed. Commonly, some or all branches of the anteriorly directed collaterals ascended to layer I to terminate, although in 1 case all terminals were in layers $\mathrm{V}$ and VI (Fig. 10). All labeled area 2 cells had principal axons that could be traced forward toward the injection site beneath area $3 \mathrm{~b}$. A few could be seen to divide and continue forward as 2 major branches.

Many anterogradely labeled fibers continued anteriorly from injection sites in the stratum of corticocortical fibers beneath area 3b (Figs. 2, 4). Obviously, none of these could be traced back through the injection site to retrogradely labeled cells of origin. However, their trajectory, hugging the white-gray matter border and following the curve of the corticocortical stratum, as delineated in autoradiographs (Fig. $2 A$ ), makes it likely that they are, indeed, corticocortical fibers arising in areas 2 , 1 , or $3 \mathrm{~b}$ and passing forward to areas $3 \mathrm{a}$ and/or 4 . Ten individual labeled axons were traced to terminal ramifications in either areas $3 a$ or 4 (Figs. 12-14). Two had terminal ramifications in both areas. The axons either cntcred the cortex through area $3 \mathrm{a}$ or curved forward to enter area 4 in the anterior bank of the central sulcus. In both areas they run very obliquely through layers VI and V, gradually ascending to layer IV, in which columnar arrays of mainly vertical terminal branches are given off. These are virtually identical to the focal terminal ramifications given off by the collaterals of retrogradely labeled corticocortical cells. No axons ending in area 3a alone (see Fig. 15) had more than a single focal termination. Approximately half of those recovered ending in area 4 had 2 or 3 focal terminations (Figs. 12, 13), which could be close together or widely separated. Some axons even had focal terminations in both the part of area 4 buried in the central sulcus and another several millimeters anterior to them in the exposed part (Fig. 13). The two axons with focal terminations in areas $3 \mathrm{a}$ and 4 had their area 4 termination in the buried part.

The injections of HRP placed in the cortex of area 1 served to label axons anterogradely in the corticocortical stratum that was injected beneath area $3 \mathrm{~b}$ in the above set of experiments. Certain injections were confined to layers I-III or IV; others extended through layers I-V or VI. From the more superficial injections, anterogradely labeled fibers descended vertically into the white matler, followed the corticocortical stratum beneath area $3 b$ for some distance and then gradually inclined into the deep layers of area $3 \mathrm{~b}$, which they traversed en route to area $3 \mathrm{a}$; there they gave rise to one or more focal, columnlike terminations (Fig. 15). None could be found that had branches to area $3 \mathrm{~b}$ as well. 


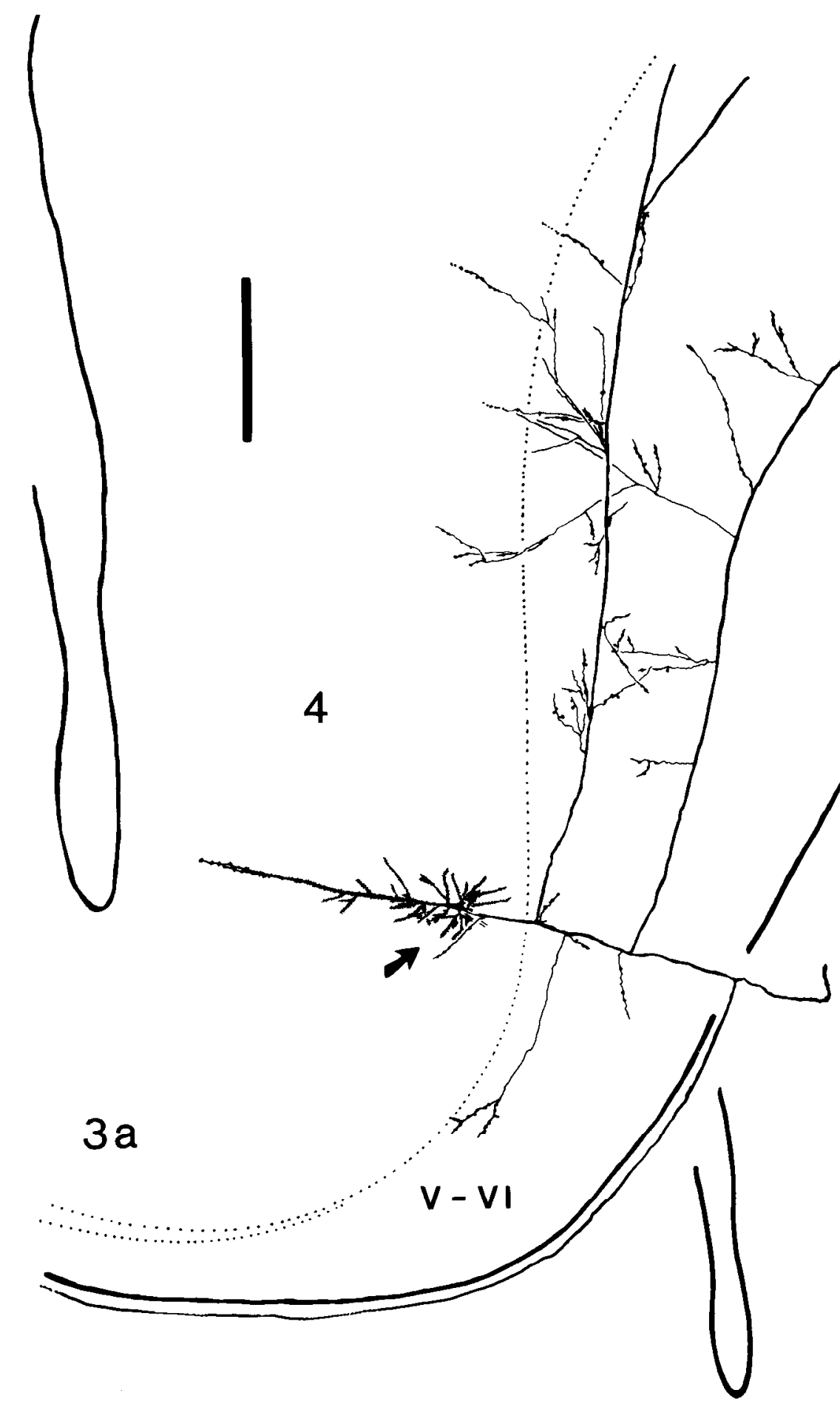



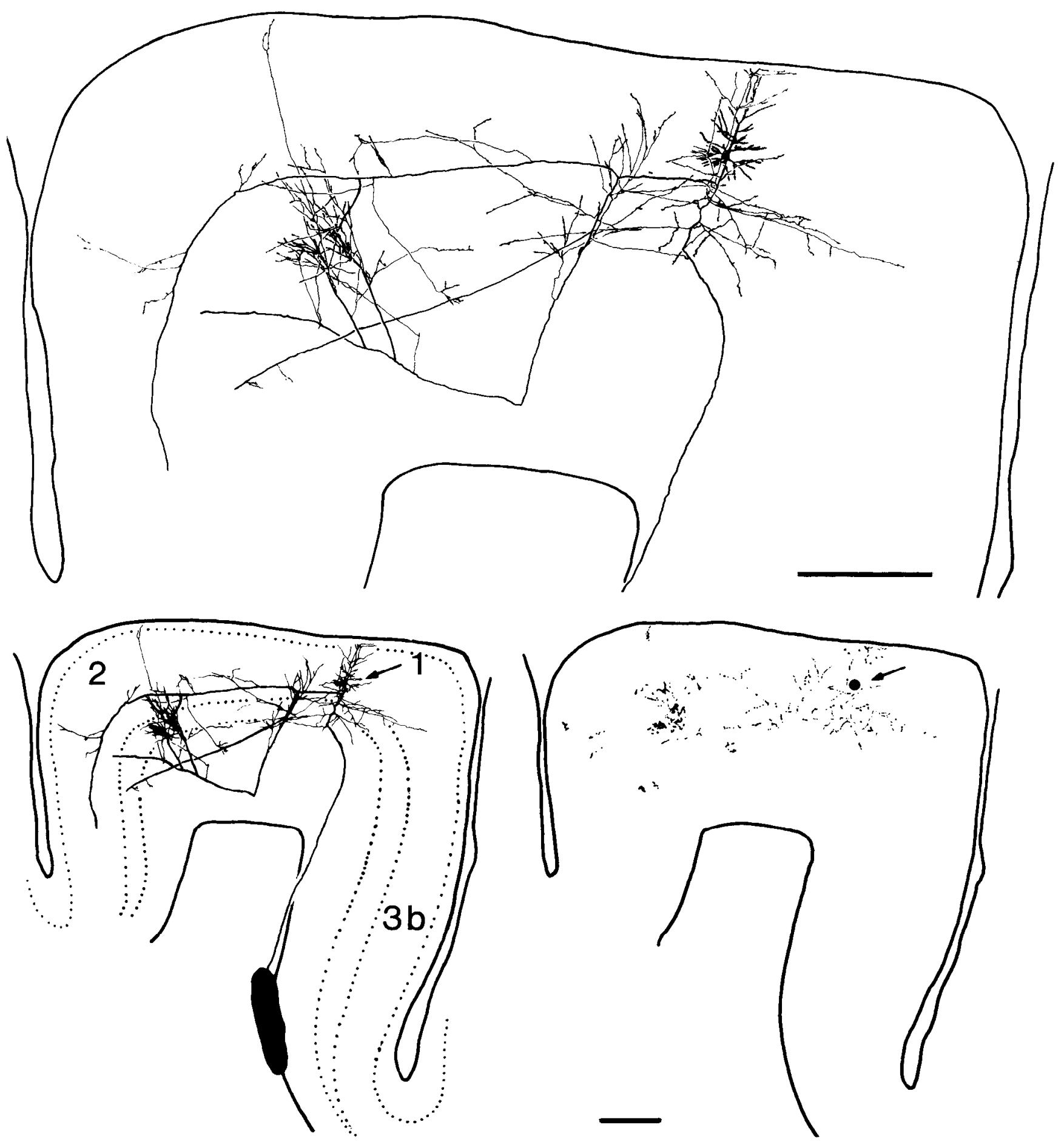

Figure 9. Retrogradely labeled corticocortical cell with soma (arrow) in area 1 , a minor collateral to area $3 \mathrm{~b}$, dense boutonal clusters in areas 1 and 2 , and major collaterals apparently continuing on toward area 5 . Bar, $500 \mu \mathrm{m}$.

From the injections that penetrated more deeply and reached layer $\mathrm{V}$, labeled fibers could be traced into the corticocortical stratum and onward to area $3 \mathrm{a}$ as just described. Some continued onward and ended in area 4. Other labeled fibers (Fig. 16), with the appearance of the major collaterals described in the first part of this study, passed anteriorly within layers III and/or V of the cortex. These descended in area $3 \mathrm{~b}$, giving rise to 1,2 , or more focal terminations having all the appearances of those described above. Similar putative collaterals ran posteriorly into area 2 and had appearances similar to those described for retrogradely labeled area 1 cells.

\section{Discussion}

The present study demonstrates the existence in the monkey sensory-motor cortex of a population of pyramidal cells that form highly specific connections, widely arborized in the horizontal direction (Fig. 11). Although the presence of collaterals on the axons of cortical pyramidal cells is well known from 


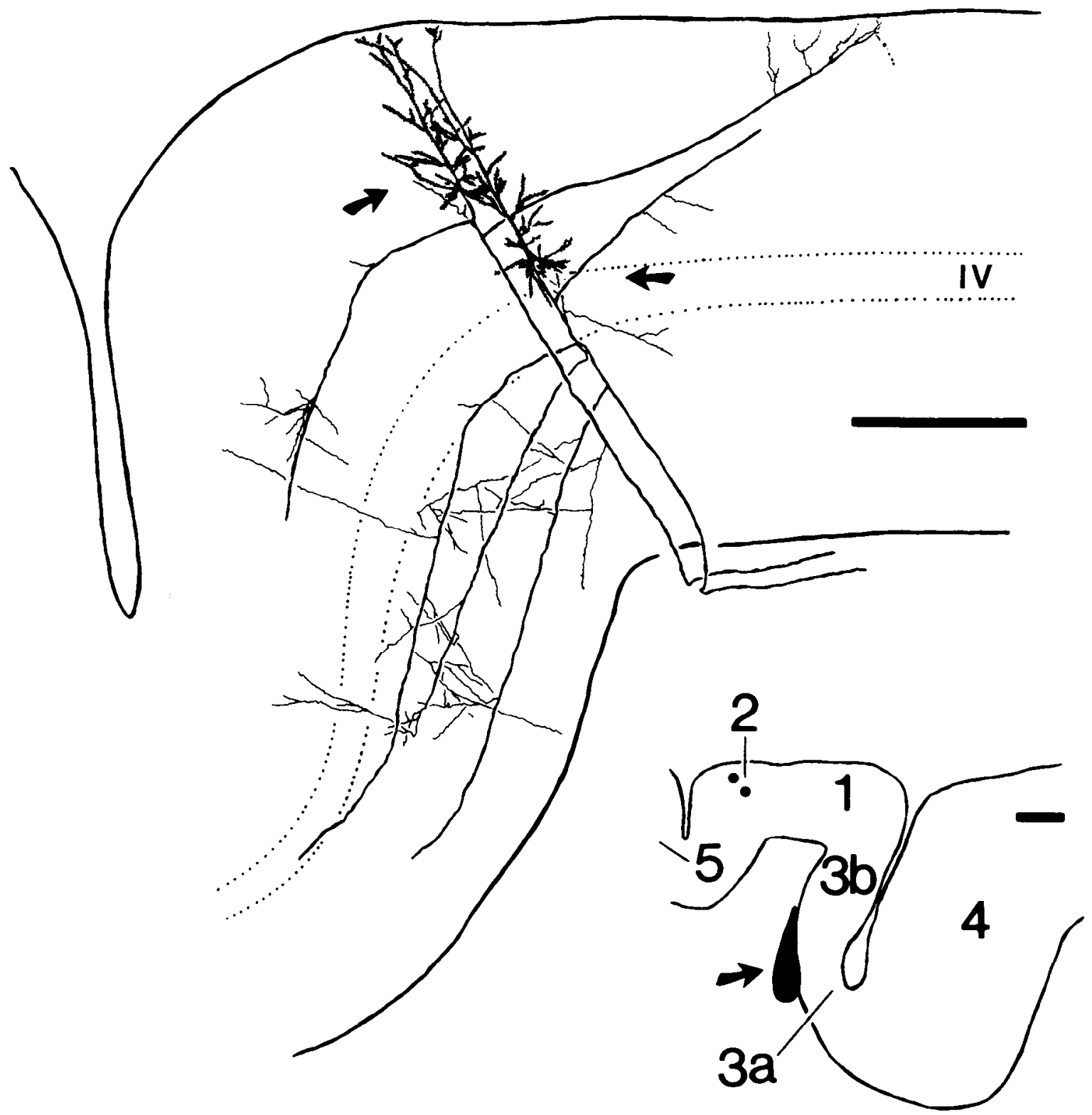

Figure 10. Two retrogradely labeled corticocortical cells with somata (arrows) in area 2 and anteriorly and posteriorly directed collaterals. Boutonal filling was not complete in these cells, but focal concentrations of terminal branches seem apparent in areas 1 and 2 and at least 2 major collaterals appear directed posteriorly towards area 5. Bars: $500 \mu \mathrm{m}, 1 \mathrm{~mm}$.

Golgi studies, it seems doubtful that the enormous extent and the specific, intra-areal distribution of their terminal ramifications were fully appreciated until the introduction of modern cell-filling methods.

In the larger part of this study, advantage was taken of the fact that axons of corticocortical neurons, linking the fields of the first somatic sensory area to one another and to the motor cortex, lie in a stratum in the white matter immediately deep to area 3b (Figs. 1, 2; Jones et al., 1978). The cells could thus be labeled more or less in isolation by small injections of HRP madc into the stratum. Subcortically projecting cells whose axons, as shown by autoradiography, are demonstrably not in the corticocortical stratum (except for those of area $3 \mathrm{~b}$ cells, which must pass through the stratum), were usually not labeled. In any case, because we selected for reconstruction a population of labeled pyramidal cells with somata in layer III, the cells ex- amined could not be projecting subcortically, as all subcortically projecting cells in SI and area 4 have somata in layers V or VI (Jones and Wise, 1977).

The destination of the principal axon of the labeled cells that was injected could not be determined, although labeled axons presumably belonging to corticocortical cells could clearly be traced beyond the injection site. Their identity tended to be confirmed by the results of the experiments in which area 1 rather than the corticocortical stratum was injected. The position at which the axons were injected in the corticocortical stratum suggests that ipsilateral areas $3 a$ and/or 4 are the most likely ultimate targets for axons of cells situated in areas 1,2 , or $3 b$ (see Fig. 4); any of these fields or area 5 are potential targets for cells situated in areas $3 a$ or 4 and projecting posteriorly in the stratum. Theoretically, the axon beyond the injection site could form the projection to distant cortical areas, which could in- 

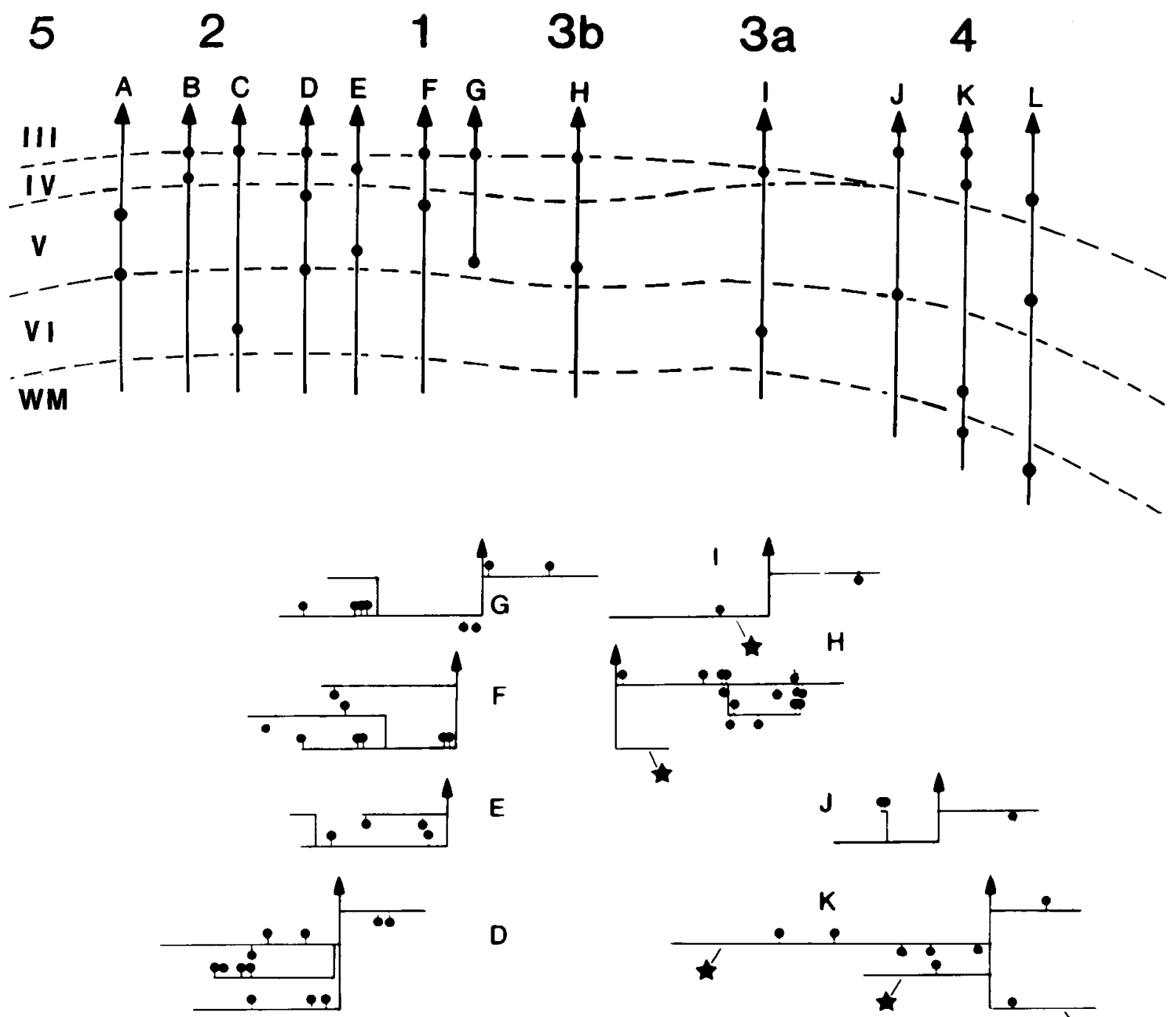

D
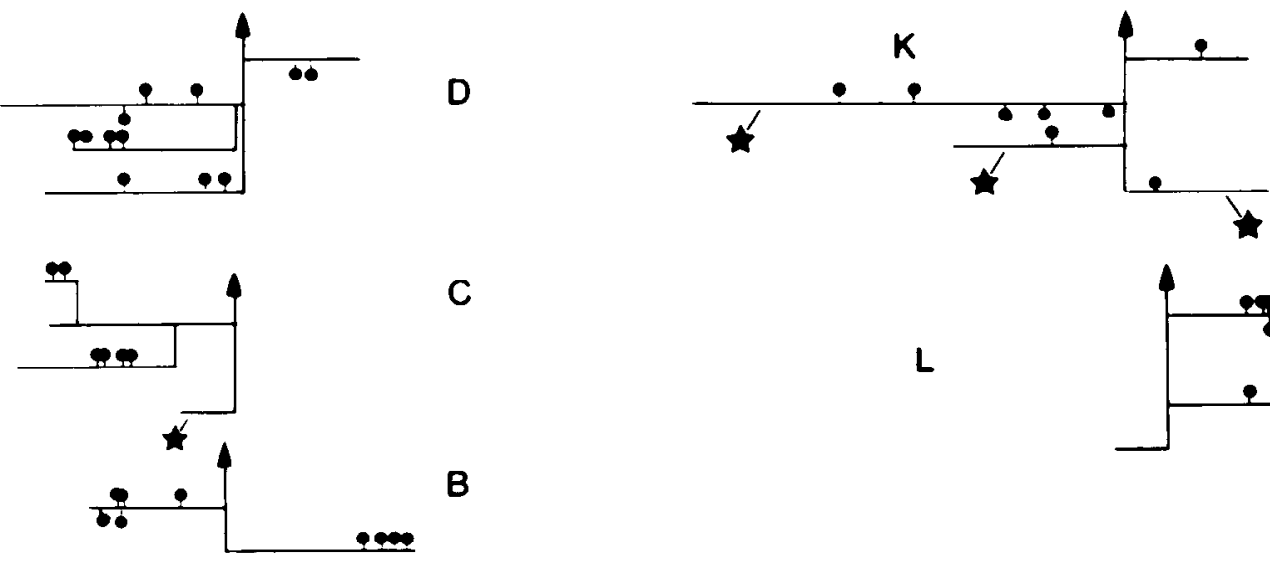

C

L

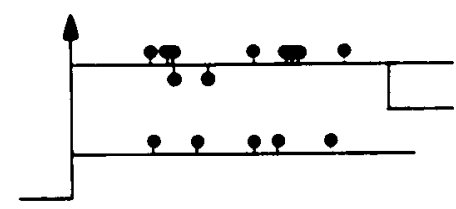

B

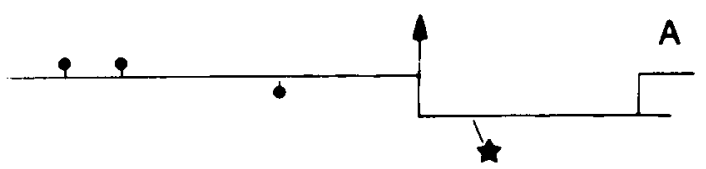

Figure 11. Schematic summary showing the varieties of branching patterns and collateral distributions observed in the study. At least 1 example of each type was encountered $(A-L)$. Top, Points of origin (dots) of major collaterals in relation to cortical layers III-VI. $W M$, white matter. Cell bodies are indicated by triangles. Bottom, Same cell varieties drawn as though seem from the side, showing the extent of the major collaterals, the terminal foci (dots) to which they gave rise, and the point of entry of certain of these into the white matter (stars). Bar, $500 \mu \mathrm{m}$.

clude, ipsilaterally, the second somatic sensory area (SII) and (for cells in areas 1 and 2 only), the supplementary motor area (Friedman et al., 1980; Jones and Wise, 1977; Jones et al., 1978, 1979). Another target might be the contralateral SI and/or SII. However, with the exception of the supplementary motor area, the axons projecting to these sites are not likely to be in the stratum injected, as indicated by autoradiography (Jones et al., 1978,1979 ), and virtually all axons anterogradely labeled beyond the injection site could be traced into areas 3a or 4 .

The earlier autoradiographic study demonstrated the follow- 


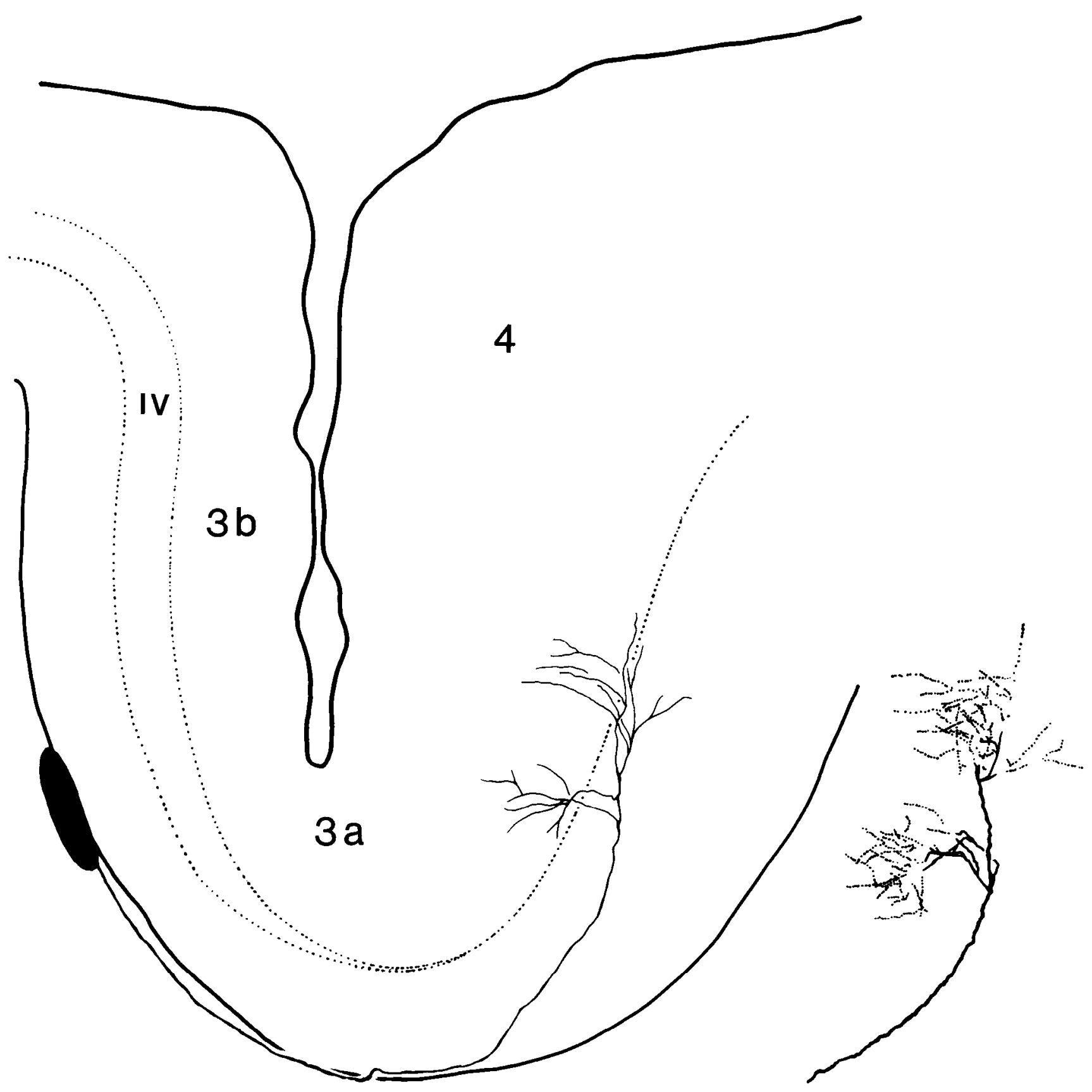

Figure 12. Presumed corticocortical afferent fiber, anterogradely labeled from an injection of HRP in the corticocortical stratum and terminating in 2 foci in area 4 . Bar, $500 \mu \mathrm{m}$.

ing: Area 2 projects mainly to areas 5,1 , and 4 ; area 1 projects mainly to areas $2,3 a$, and 4 ; area $3 b$ projects to areas 1 and $3 a$; area $3 a$ projects to areas $3 b$ and 1 ; and area 4 projects to areas $3 \mathrm{a}, 1,2$, and 5 . Similar results had been obtained by Vogt and Pandya (1977), using degeneration methods. Of particular note is the lack of projections from areas $3 b$ and $3 a$ to area 4 , which has functional implications (Jones and Porter, 1980). Generally speaking, the present rcsults arc in conformity with the earlier studies, although the nature of the present experiments precluded the tracing of the principal axons of the identified cells to their ultimate destinations within the cortex.
Another point for comparison with the earlier autoradiographic study is the marked predilection for the terminal ramifications of the major collaterals of the corticocortical cells to form columnlike foci. This does not always become apparent until the pattern of boutonal distribution is plotted, for branches arising at different points along the lengths of different collaterals can obscure the focused nature of the terminations. It was remarkable, however, that terminal branches arising from widely separated collaterals would often converge on the same terminal column. The autoradiographic study showed that a focal injection of tracer in any of the sensory-motor fields led to multiple, 


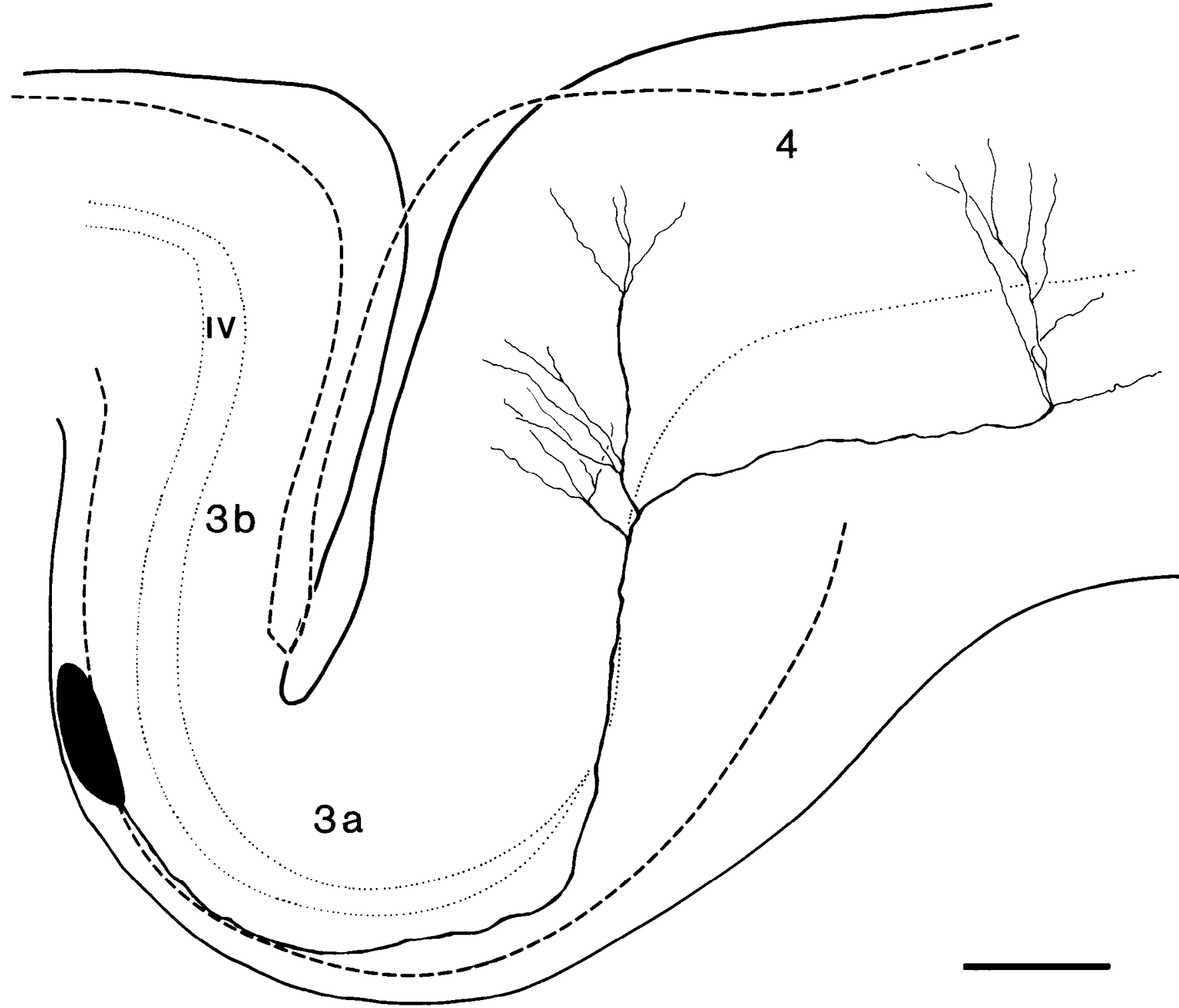

Figure 13. Presumed corticocortical afferent fiber anterogradely labeled from an injection beneath area $3 \mathrm{~b}$ and ending in 3 foci in both sulcal and surface parts of area 4 . Bar, $500 \mu \mathrm{m}$.

columnlike foci of labeled terminal ramifications in layers I-IV of the same field and of the other fields to which the injected field projected (Jones et al., 1975, 1978). These tended to be in anteroposterior line with the injection site across the central sulcus. The columnar foci of terminal ramifications of the collaterals of single cells, as labeled in the present study, would seem to be an obvious morphological basis for the "columnar" autoradiographic labeling patterns. In other words, the columnlike pattern of corticocortical connectivity is based upon the pattern of collateral terminations of individual cells. One would anticipate, from the autoradiography, that the ultimate terminations of the principal axons of the corticocortical cells would also be focal and columnlike, and this, too, tends to be confirmed by the experiments with injections in area 1 and by the terminal patterns of axons traced beyond the white matter injections into areas $3 a$ and 4 .

Autoradiography shows that the focal columns of labeled corticocortical terminations ensuing from a localized injection of tritiated amino acids are parts of short strips that tend to be elongated in the mediolateral dimension. Because the terminal ramifications of the collaterals of individual cells tend to be more focal, this would suggest that the terminations of collaterals arising from several corticocortical cells may be aligned to form the strips. This supposition tends to be confirmed by a correlative retrograde labeling study in which a focal injection of HRP in one of the sensory-motor fields led to retrograde labeling of multiple foci, each composed of numerous corticocortical, pyramidal cell somata, in the same and in other appropriate fields (Jones et al., 1978). In other words, the clustered pyramidal cell somata revealed by this previous type of retrograde labeling may have coincident or closely aligned, patchy collateral arborizations of the type demonstrated in the present study.

The pattern of horizontal connectivity demonstrated here is composed of axons that are likely to make excitatory synapses (Phillips, 1959; Winfield et al., 1981). It contrasts with the pat- 


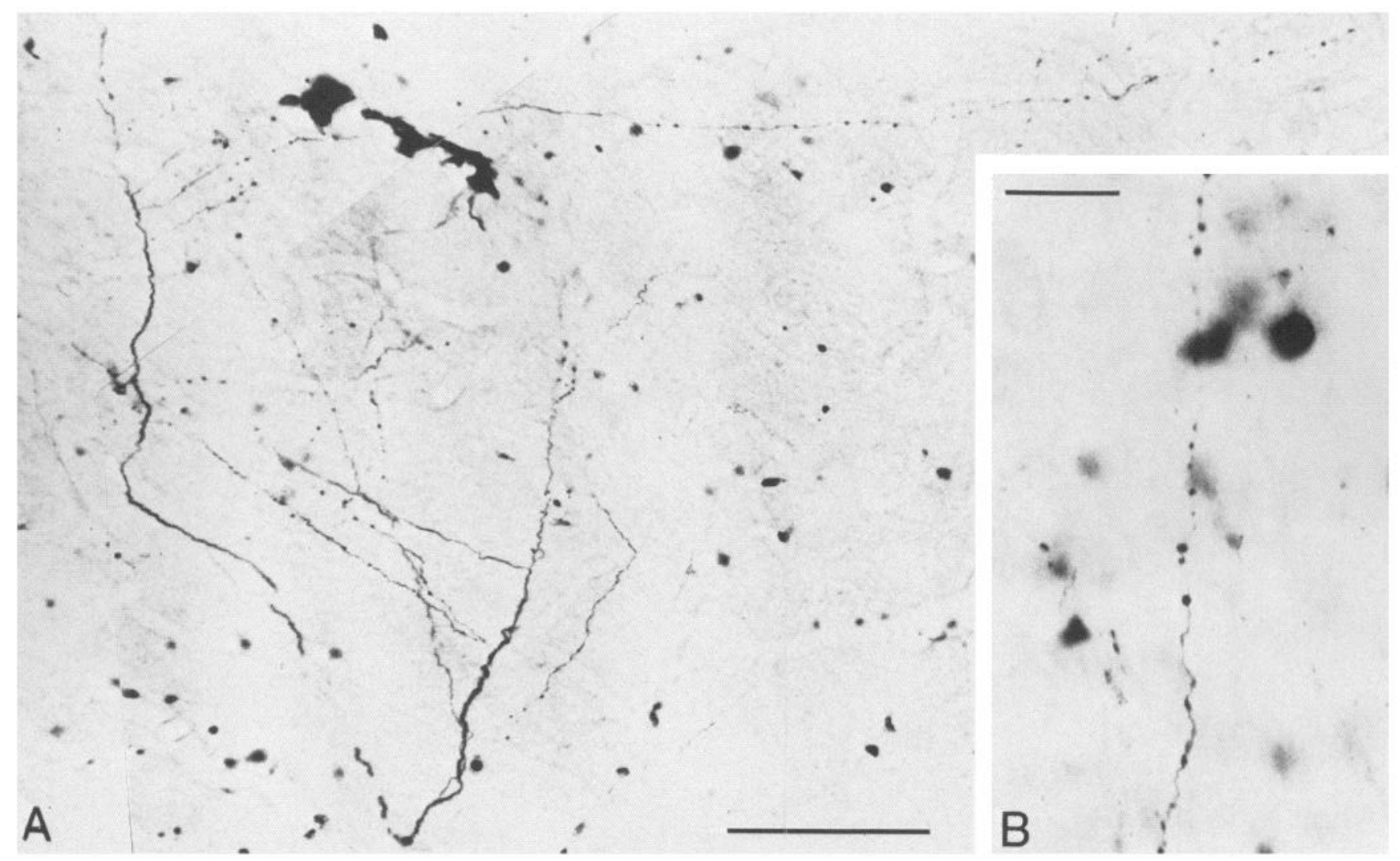

Figure 14. A, Photomicrograph of part of an anterogradely labeled corticocortical termination found in the same sections and close to that illustrated in Figure 13. B, Higher magnification of a vertical branch (out of focus to left in $A$ ), with a linear array of boutons very similar to those illustrated on the corticocortical collateral termination in Figure 5. Calibration bars, $100 \mu \mathrm{m}(A) ; 25 \mu \mathrm{m}(B)$.

tern of vertical or interlaminar connections formed by 2 other populations of cells: certain pyramidal and spiny nonpyramidal cells (Gilbert and Wiesel, 1979, 1983; Jones, 1975a; Martin and Whitteridge, 1984; McGuire et al., 1984), which are also probably excitatory, and certain ${ }^{3} \mathrm{H}-\mathrm{GABA}$-accumulating, nonspiny, nonpyramidal cells, which are believed to be inhibitory (DeFelipe and Jones, 1985; Hendry and Jones, 1981; Somogyi et al., 1981, 1983). The vertical connections are perhaps major links ensuring that cells within a functional cortical column share similar functional properties, although direct thalamic inputs at several levels of the column may also be important (e.g., Bullier and Henry, 1979; Malpeli, 1983). By contrast, horizontal connections of the kind demonstrated in the present study could form the basis for interactions between columns both in the same and in the other areas of the sensory-motor cortex. These focal connections, formed by single cells, may be linking homotopic parts of the different half-body maps in areas $3 \mathrm{a}, 3 \mathrm{~b}, 1$, and 2 , though this has not yet been tested. By interconnecting areas and parts of the same area, they may also be promoting modality and place convergence between functional columns. Iwamura et al. (1980, 1983a, b, 1985), have predicted that such connections would be necessary to explain the construction of the complex receptive fields of clusters of neurons that they and others have observed in areas 1 and 2 of conscious monkeys. These neurons often have receptive fields on more than one finger, show convergence of inputs from cutaneous and deep receptors and/or from hairy and glabrous skin, and are often movement- and direction-selective. These properties are quite unlike those of neurons in areas $3 a$ and $3 b$, which have receptive fields on one finger and tend not to show convergence of deep and superficial inputs nor (in area 3b) of inputs from glabrous and hairy skin, and they are not direction-selective. Because the thalamic cells projecting selectively to areas $3 \mathrm{a}, 3 \mathrm{~b}$, 1, and 2 (Jones, 1983; Jones and Friedman, 1982) tend to have nonconvergent receptive fields and modality properties (Jones et al., 1982; Kaas et al., 1984; Poggio and Mountcastle, 1963), the implication is that convergent properties of the type highlighted by Iwamura et al. occur through intercortical connections.

Certain pyramidal and spiny nonpyramidal neurons in the primary visual cortex of the cat and monkey also possess relatively long collaterals ending in clustered axonal arborizations (Gilbert and Wiesel, 1983; Martin and Whitteridge, 1984; Rockland and Lund, 1983; Rockland et al., 1982). These are confined to area 17, and the cells thus resemble those illustrated in Figure 6 , although they could have axons projecting to other areas. In the somatic sensory cortex the collaterals of the cells studied here not only form clustered terminations in their own areas but can also extend intracortically for long distances into other areas and form clustered arborizations in these as well. Their length, large diameter, and focused terminations lead us to suggest that they form a major route for communication not only between columns in the same area but between columns in closely linked subdivisions of the sensory-motor areas. Their exact mode of termination awaits further study, as does the comparative physiology of the columns containing the parent cells and those to which they project. The types of cells upon which the terminations occur could, for example, determine whether the columns in which the collaterals terminate are excited or inhibited by the column containing the parent cell. Two 


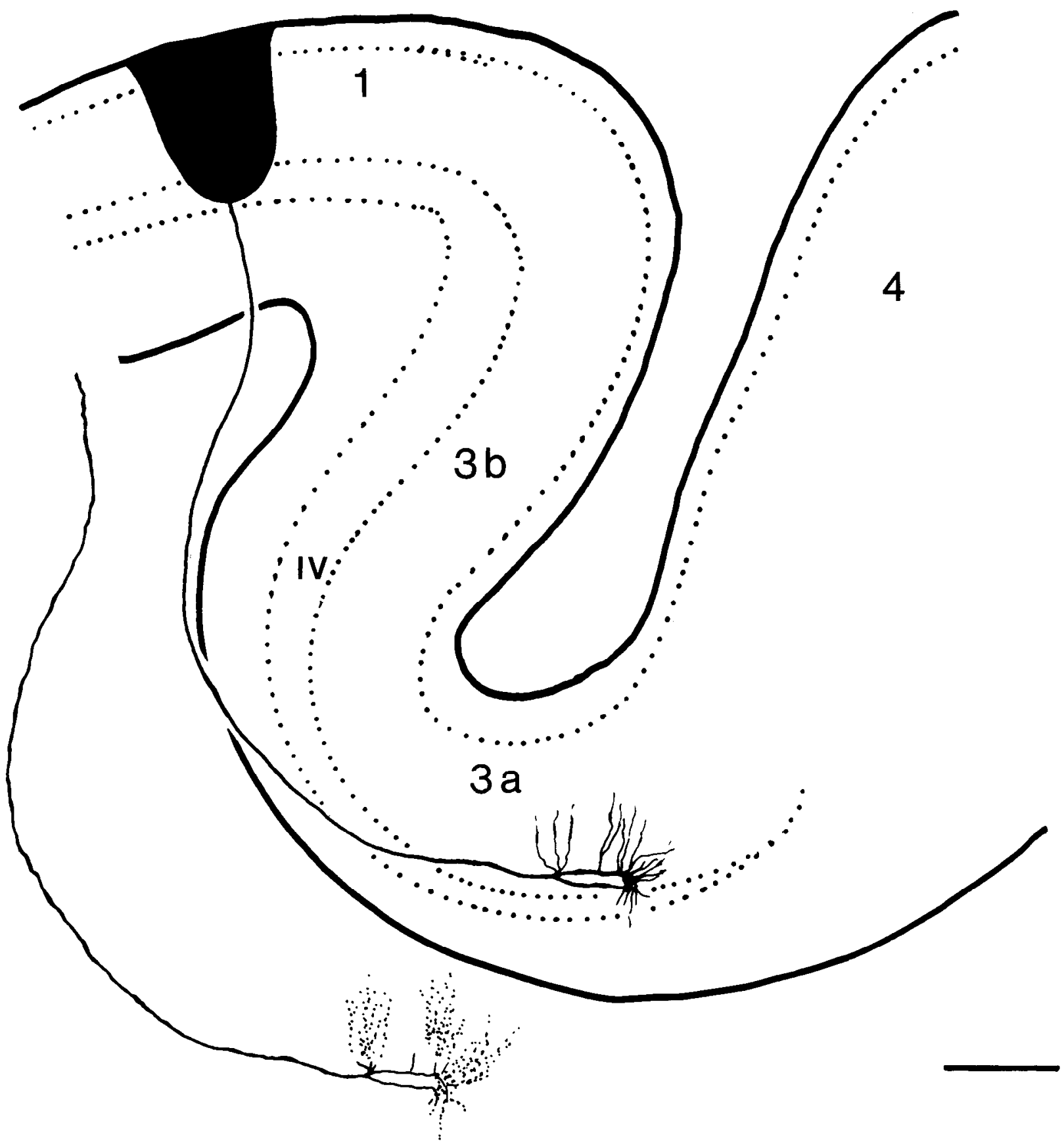

Figure 15. Corticocortical afferent fiber demonstrated in area 3a following injection of HRP in the superficial layers of area 1. Bar, $500 \mu \mathrm{m}$.

such interconnected columns might have complementary instead of identical properties, as, e.g., Matsubara et al. (1985) have shown for interconnected patches of orientation columns in the cat visual cortex.

\section{References}

Adams, J. C. (1977) Technical considerations on the use of horseradish peroxidase as a neuronal marker. Neuroscience 2: 141-146.

Blasdel, G. G., and J. S. Lund (1983) Termination of afferent axons in macaque striate cortex. J. Neurosci. 3: 1389-1413.

Bullicr, J., and G. H. Henry (1979) Laminar distribution of first order neurons and afferent terminals in cat striate cortex. J. Neurophysiol. 42: $1271-1281$.

Conley, M., and E. G. Jones (1984) Laminar terminations of individual afferent axons in SI cortex in Macaca. Neurosci. Abstr. 10: 495.
DeFelipe, J., and E. G. Jones (1985) Vertical organization of $\gamma$-aminobutyric acid-accumulating intrinsic neuronal systems in monkey cerebral cortex. J. Neurosci. 5: 3246-3260.

DeFelipe, J., M. Conley, and E. G. Jones (1985) Multiple, long-range focal collateralization of single corticocortical axons in monkey sensory-motor cortex. Neurosci. Abstr. 11: 904.

Friedman, D. P., and E. G. Jones (1981) Thalamic input to areas 3a and 2 in monkeys. J. Neurophysiol. 45: 59-85.

Friedman, D. P., E. G. Jones, and H. Burton (1980) Representation pattern in the second somatic sensory area of the monkey cerebral cortex. J. Comp. Neurol. 192: 21-41.

Gardner, E. P., and R. M. Costanzo (1980) Neuronal mechanisms underlying direction sensitivity of somatosensory cortical neurons in awake monkeys. J. Neurophysiol. 43: 1342-1352.

Gilbert, C. D. (1983) Microcircuitry of the visual cortex. Annu. Rev. Neurosci. 61: 217-248. 


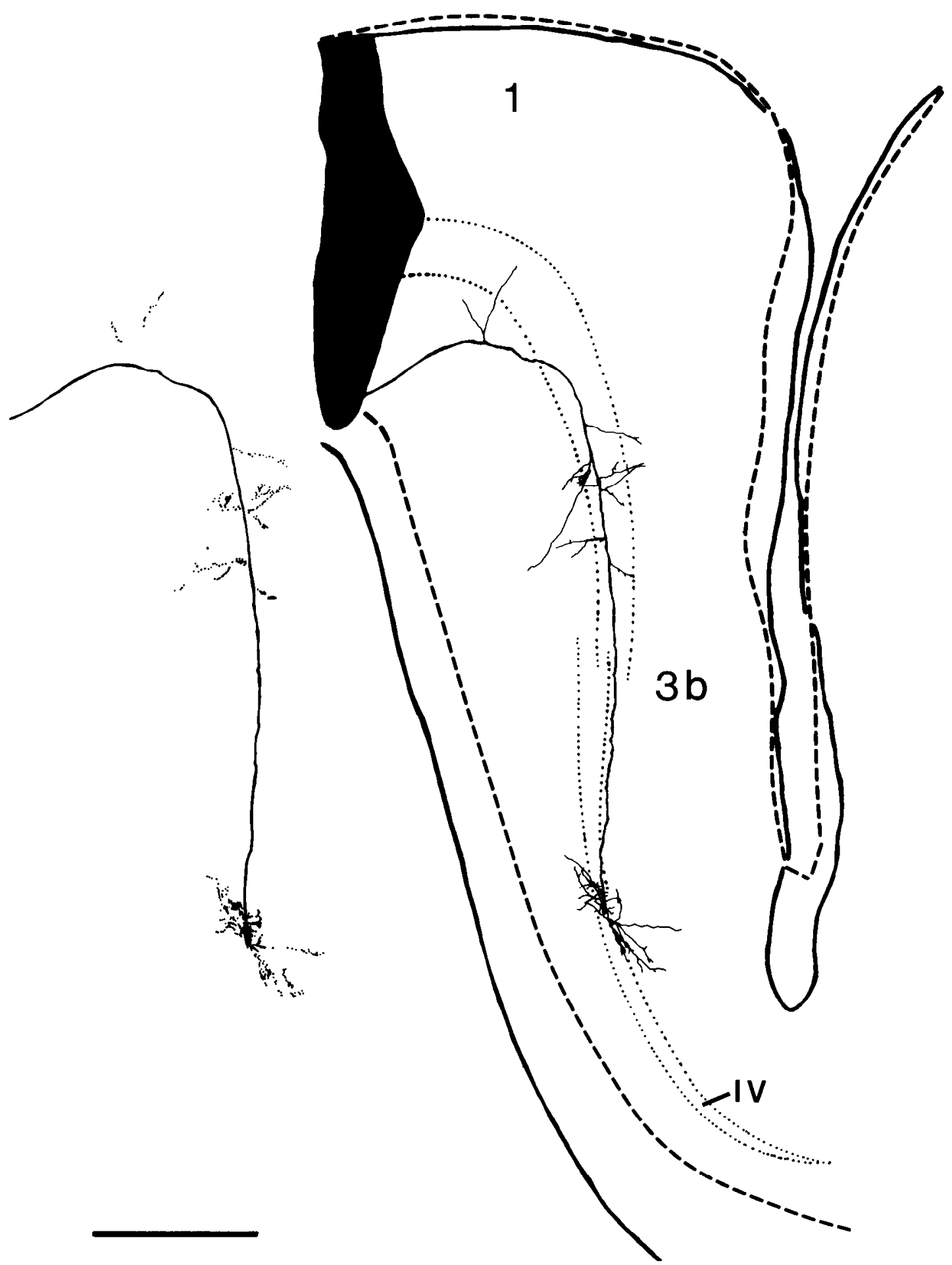

Figure 16. Presumed collateral fiber, injected in area 1 and distributing focal, boutonal concentrations primarily in area $3 \mathrm{~b}$. Bar, $500 \mu \mathrm{m}$.

Gilbert, C. D., and T. N. Wiesel (1979) Morphology and intracortical projections of functionally characterised neurones in the cat visual cortex. Nature 280: 120-125.

Gilbert, C. D., and T. N. Wiesel (1983) Clustered intrinsic connections in cal visual cortex. J. Neurosci. 3: 1116-1133.

Hendry, S. H. C., and E. G. Jones (1981) Sizes and distribution of intrinsic ncurons incorporating tritiated GABA in monkey sensorymotor cortex. J. Neurosci. 1: 390-408.

Hyvärinen, J., and A. Poranen (1978) Receptive field integration and submodality convergence in the hand area of the post-central gyrus of the alert monkey. J. Physiol. (Lond.) 283: 539-556.
Iwamura, Y., M. Tanaka, and O. Hikosaka (1980) Overlapping representation of the fingers in the somatosensory cortex (area 2) of the conscious monkey. Brain Res. 197: 516-520.

Iwamura, Y., M. Tanaka, M. Sakamoto, and O. Hikosaka (1983a) Functional subdivisions representing different finger regions in area 3 of the first somatosensory cortex of the conscious monkey. Exp. Brain Res. 51: 315-326.

Iwamura, Y., M. Tanaka, M. Sakamoto, and O. Hikosaka (1983b) Converging patterns of finger representation and complex properties of neurons in area 1 of the first somatosensory cortex in the conscious monkey. Exp. Brain Res. 51: 327-337. 
Iwamura, Y., M. Tanaka, M. Sakamoto, and O. Hikosaka (1985) Diversity in receptive field properties of vertical neuronal arrays in the crown of the postcentral gyrus of the conscious monkey. Exp. Brain Res. 58: 400-411.

Jones, E. G. (1975a) Varieties and distribution of non-pyramidal cells in the somatic sensory cortex of the squirrel monkey. J. Comp. Neurol. 160: 205-268.

Jones, E. G. (1975b) Lamination and differential distribution of thalamic afferents within the sensory motor cortex of the squirrel monkey. J. Comp. Neurol. 160: 167-204.

Jones, E. G. (1983) Lack of collateral thalamocortical projections to fields of the first somatic sensory cortex in monkeys. Exp. Brain Res. 52: $375-384$.

Jones, E. G., and D. P. Friedman (1982) Projection pattern of functional components of thalamic ventrobasal complex on monkey somatosensory cortex. J. Neurophysiol. 48: 521-544.

Jones, E. G., and R. Porter (1980) What is area 3a? Brain Res. Rev. 2: $1-43$

Jones, E. G., and S. P. Wise (1977) Size, laminar and columnar distribution of efferent cells in the sensory-motor cortex of monkeys. $J$. Comp. Neurol. 175: 391-438.

Jones, E. G., H. Burton, and R. Porter (1975) Commissural and cortico-cortical "columns" in the somatic sensory cortex of primates. Science 190: 572-574.

Jones, E. G., J. D. Coulter, and S. H. C. Hendry (1978) Intracortical connectivity of architectonic fields in the somatic sensory, motor and parietal cortex of monkeys. J. Comp. Neurol. 181: 291-348.

Jones, E. G., J. D. Coulter, and S. P. Wise (1979) Commissural columns in the sensory-motor cortex of monkeys. J. Comp. Neurol. 188: 113-136.

Jones, E. G., D. P. Friedman, and S. H. C. Hendry (1982) Thalamic basis of place- and modality-specific columns in monkey somatosensory cortex: a correlative anatomical and physiological study. J. Neurophysiol. 48: 545-568.

Kaas, J. H., R. J. Nelson, M. Sur, C.-S. Lin, and M. M. Merzenich (1979) Multiple representations of the body within the primary somatosensory cortex of primates. Science 204: 521-523.

Kaas, J. H., R. J. Nelson, M. Sur, R. W. Dykes, and M. M. Merzenich (1984) The somatotopic organization of the ventroposterior thalamus of the squirrel monkey, Saimiri sciureus. J. Comp. Neurol. 226 . 111-140.

Lorente de Nó, R. (1949) Cerebral cortex: Architecture, intracortical connections, motor projections. In Physiology of the Nervous System, 3rd Ed., J. F. Fulton, ed., pp. 288-313. Oxford U. P., London.

Malpeli, J. G. (1983) Activity of cells in area 17 of the cat in absence of input from layer $A$ of lateral geniculate nucleus. J. Neurophysiol. 49: 595-610.

Martin, K. A. C., and D. Whitteridge (1984) Form, function and intracortical projections of spiny neurones in the striate visual cortex of the cat. J. Physiol. (Lond.) 353: 463-504.
Matsubara, J., M. Cynader, N. V. Swindale, and M. P. Stryker (1985) Intrinsic projections within visual cortex: Evidence for orientationspecific local connections. Proc. Natl. Acad. Sci. USA 82: 935-939.

McGuire, B. A., J.-P. Hornung, C. D. Gilbert, and T. N. Wiesel (1984) Patterns of synaptic input to layer 4 of cat striate cortex. J. Neurosci. 4: 3021-3033.

Mountcastle, V. B. (1957) Modality and topographic properties of single neurons of cat's somatic sensory cortex. J. Neurophysiol. 20: 408-434.

Nelson, R. J., M. Sur, D. J. Felleman, and J. H. Kaas (1980) Representations of the body surface in postcentral parietal cortex of Macaca fascicularis. J. Comp. Neurol. 192: 611-643.

Phillips, C. G. (1959) Actions of antidromic pyramidal volleys on single Betz cells in the cat. Q. J. Exp. Physiol. 44: 1-25.

Phillips, C. G., T. P. S. Powell, and M. Wiesendanger (1971) Projections from low threshold muscle afferents of hand and forearm to area 3a of baboon's cortex. J. Physiol. (Lond.) 217: 419-446.

Poggio, G. F., and V. B. Mountcastle (1963) The functional properties of ventrobasal thalamic neurons studied in unanesthetized monkeys. J. Neurophysiol. 26: 775-806.

Powell, T. P. S., and V. B. Mountcastle (1959) Some aspects of the functional organization of the cortex of the postcentral gyrus of the monkey: A correlation of findings obtained in a single unit analysis with cytoarchitecture. Bull. Johns Hopkins Hosp. 105: 133-162.

Rockland, K. S., and J. S. Lund (1983) Intrinsic laminar lattice connections in primate visual cortex. J. Comp. Neurol. 216: 303-318.

Rockland, K. S., J. S. Lund, and A. L. Humphrey (1982) Anatomical banding of intrinsic connections in striate cortex of the tree shrew (Tupaia glis). J. Comp. Neurol. 209: 41-48.

Somogyi, P., A. Cowey, N. Halaśz, and T. F. Freund (1981) Vertical organization of neurones accumulating $\left[{ }^{3} \mathrm{H}\right] \gamma-\mathrm{GABA}$ in visual cortex of rhesus monkey. Nature 294: 761-763.

Somogyi, P., A. Cowey, Z. F. Kisvaŕday, T. F. Freund, and J. Szentágothai (1983) Retrograde transport of gamma-amino (H-3) butyric acid reveals specific interlaminar connections in the striate cortex of monkeys. Proc. Natl. Acad. Sci. USA 80: 2385-2389.

Vogt, B. A., and D. N. Pandya (1977) Cortico-cortical connections of somatic sensory cortex (areas 3,1 and 2 ) in the rhesus monkey. J. Comp. Neurol. 177: 179-191.

Werner, G., and B. L. Whitsel (1968) Topology of the body representation in somatosensory area I of primates. J. Neurophysiol. 31: 856869.

Winfield, D. A., R. N. L. Brooke, J. J. Sloper, and P. S. Powell (1981) A combined Golgi-electron microscopic study of the synapses made by the proximal axon and recurrent collaterals of a pyramidal cell in the somatic sensory cortex of the monkey. Neuroscience 6: 12171230 . 